\title{
Ability of Comprehensive Geriatric Assessment to Detect Frailty
}

\author{
Moatassem S. Amer1, Tamer M. Farid1, Ekrami E. Abd El-Rahman1, \\ Deena M. EL-Maleh1 ${ }^{*}$, Omar H. Omar ${ }^{2}$, Randa A. Mabrouk ${ }^{3}$ \\ ${ }^{1}$ Geriatrics and Gerontology Department, Faculty of Medicine, Ain Shams University, Cairo, Egypt \\ ${ }^{2}$ Radiodiagnosis Department, Faculty of Medicine, Ain Shams University, Cairo, Egypt \\ ${ }^{3}$ Clinical Pathology Department, Faculty of Medicine, Ain Shams University, Cairo, Egypt \\ Email: ${ }^{*}$ doc dodi80@yahoo.com
}

Received 12 February 2014; revised 28 March 2014; accepted 21 April 2014

Copyright (C) 2014 by authors and Scientific Research Publishing Inc.

This work is licensed under the Creative Commons Attribution International License (CC BY).

http://creativecommons.org/licenses/by/4.0/

(c) (i) Open Access

\begin{abstract}
Background and Aim of the Work: Frailty is a state of reduced physiological reserve associated with increased susceptibility to disability. It is associated with a high morbidity and mortality. This work assessed the ability of comprehensive geriatric assessment to detect frailty in elderly patients. Subjects and Methods: A total number of 104 elderly patients (above 60 years old) were included in this study and they were subjected to a comprehensive geriatric assessment (CGA) including: (history and full clinical examination, Mini mental status examination (MMSE), Geriatric depression scale (GDS), Activities of daily living (ADL), Instrumental activities of daily living (IADL). The patients were divided into frail and non-frail groups using Fried's criteria as applied by AvilaFunes et al., 2008, each group included 52 patients. Results: There were no significant differences between the two groups regarding age gender or smoking habits. But there was higher percentage of ADL, IADL dependence in addition to higher incidence of depression and cognitive impairment among frail cases. Conclusion: Comprehensive geriatric assessment can be used to detect frailty and its associated impairment and comorbidities.
\end{abstract}

\section{Keywords}

Frailty, Comprehensive Geriatric Assessment

\section{Introduction}

Fried et al. defined frailty as: "A physiologic syndrome characterized by decreased reserve and resistance to

*Corresponding author. 
stressors, resulting from cumulative decline across multiple physiologic systems, and causing vulnerability to adverse outcomes" [1]. Frailty represents a state of reduced homeostasis and resistance to stress that leads to increased vulnerability and risk of adverse outcomes such as the progression of disease, falls, disability and premature death [2].

Frailty is the special mandate of the geriatrician. The essence of management in frailty is to embrace the complexity of the patients and their needs for care. When we do our jobs well, this is what geriatricians do. We have complex patients (i.e. those with multiple needs, and a multifactorially determined state) on whom we apply a complex intervention (Comprehensive Geriatric Assessment and multidisciplinary care) to achieve a variety of ends [3].

Comprehensive geriatric assessment (CGA) is a multidimensional inter-disciplinary diagnostic process focused on determining a frail elderly person's medical, psychological and functional capability in order to develop a coordinated and integrated plan for treatment and long-term follow-up [2].

Domains of CGA include: medical assessment (problem list, co-morbid conditions, medication review, nutritional status), functional assessment (basic activities of daily living (ADLs), Instrumental activities of daily living (IADL), Activity/exercise status, gait and balance), psychological assessment (mental status and mood testing), social and environmental assessment. Two or more of the following are markers of frailty:

- inability to perform one or more basic ADLs in the 3 days before admission

- a stroke in the past 3 months $\bullet$ depression $\bullet$ dementia

• history of falls $\bullet$ one or more unplanned admissions in the past 3 months

- difficulty walking $\bullet$ malnutrition $\bullet$ prolonged bed rest $\bullet$ incontinence [2].

Current evidence strongly suggests that ward-based CGA should now be considered the standard of care for the frail elderly inpatient as comprehensive assessment of frail older people may reduce short-term mortality and increase the chances of living at home in one year. An improvement in physical function is demonstrable in 6 months. Reduction in hospital readmissions and placement in care homes as well as improvement in quality of life and in cognition is shown in 12 months. These have all been recognized as important markers of effective care for the frail older patient [2].

Aim of the study: To compare frail and non-frail elderly people using CGA.

\section{Patients and Methods}

\subsection{Study Design and Setting}

The study is a case-control study. 104 Elderly patients (60 years old and above), both males and females were recruited from Ain Shams University hospital from January 2011 till December 2012. They were divided into two groups:

Cases Group: 52 frail elderly 60 years and older diagnosed by Fried's criteria [4] as applied by Avila-Funes et al., 2008 [5]. The participants were considered to be "frail" if they had three or more frailty components among the five criteria.

Controls Group: 52 elderly 60 years and older. They are not frail or have 2 or less of frailty criteria.

\subsection{Data Collection}

Every participant was subjected to the following:

1-Informed oral or written consent.

2-Comprehensive geraitric assessment including:

a) Complete medical history.

b) Physical examination.

c) Mini mental status examination (MMSE) [6].

The MMSE comprises 30 questions: a) Ten devoted to orientation, b) Three items requiring registration of new information (repeating three words), c) Five questions addressing attention and calculation, d) Mental control questions requiring patient to make five serial subtractions of 7 from 100 or spell word backward), e) Three recall items, f) Eight items assessing language skills (two naming items, repeating phrase, following a three-step command, reading and following a written command and writing a sentence), and g) one construction question (copying a figure consisting of two overlapping pentagons). (The Arabic version used in this study was done by 
El-Okl et al. [7].

d) Geriatric depression scale (GDS) [8].

It consists of items showing highest correlation with the depressive symptoms. The cut-off point is [5] for significant depressive symptomology. The Arabic version of the test was applied by Shehta et al., [9].

e) Activities of daily living (ADL) [10].

Measurement of functional status is a cardinal component of office assessment of older persons. Basic activities of daily living assess the ability of the patient to complete basic self-care tasks (e.g. bathing-dressing-toileting-transfer-continence and feeding). An Arabic version of the test was applied. El-Sherpiny et al. [11].

f) Instrumental activities of daily living (IADL) [12].

It measures the patient's ability to maintain an independent household (e.g. shopping for groceries-driving or using public transportation, using the telephone, meal preparation, housework, taking medications, handling finances). An Arabic version of the test was applied [13].

The results of ADI \& IADL assessment are as follows:

Independent; if they reported being able to carry out all activities without assistance

Dependent: if they needed assistance of any degree in all activities.

Assisted: if they are receiving assistance of any degree in some but not all activities.

3-Frailty was defined according to the construct previously validated by Fried et al. in the Cardiovascular Health Study [14]. All five components from the original phenotype were retained; however, the metrics used to characterize the frailty criteria were slightly different and defined as follows [5]:

- Shrinking-Recent and unintentional weight loss of $\geq 3 \mathrm{~kg}$ in the prior year was identified and body mass index calculated. Participants who answered "yes" for weight loss or had a body mass index $<21 \mathrm{~kg} / \mathrm{m}^{2}$ were considered to be frail for this component.

- Poor endurance and energy - As indicated by self report of exhaustion, identified by two questions from the Center for Epidemiological Studies-Depression scale (CES-D): "I felt that everything I did was an effort" and "I could not get going." Participants were asked: "How often, in the last week, did you feel this way?" 0 = rarely or none of the time; 1 = some or a little of the time; 2 = a moderate amount of the time; or $3=$ most of the time. Participants answering " 2 " or "3" to either of these questions were considered as frail by exhaustion.

- Slowness-Meets criteria for frailty if time to walk $6 \mathrm{~m}$ was $\geq 8$ seconds for height $\leq 173 \mathrm{~cm}$ or $>7$ seconds for height $>173 \mathrm{~cm}$ in males, and $\geq 8$ seconds for height $\leq 159 \mathrm{~cm}$ or $>7$ seconds for height $>159 \mathrm{~cm}$ in females.

- Weakness-Participants answering "yes" to the following question were categorized as frail for this component: "Do you have difficulty rising from a chair?"

- Low physical activity-A single response was used to estimate physical activity. Individuals who denied doing daily leisure activities such as walking or gardening and/or denied doing some sport activity per week were categorized as physically inactive. Those who reported doing them were considered to be active.

Patients who had 3 of the 5 items were diagnosed as frail.

\section{Data Management}

Analysis of data was performed by using the 12th version of Statistical Package for Social Science (SPSS). Description of all data in the form of mean (M) and standard deviation (SD) for all quantitative variables was done. Frequency and percentage was done for all qualitative variables. Comparison between quantitative variables was done using t-test to compare to compare two groups and ANOVA (analysis of variance) to compare more than two groups. Comparison of qualitative variables was done using the Chi-square test. Correlation coefficient also was used to find linear relation between different variables using r-test or Sperman correlation co-efficient. Significant level measured according to $\mathrm{P}$ value (probability), $\mathrm{P}>0.05$ is insignificant, $\mathrm{P}<0.05$ is significant and $\mathrm{p}$ $<0.01$ is highly significant.

\section{Results}

The study included 104 elderly participants (60 years old and above), both males and females were recruited from Ain Shams University hospital. The participants were divided into a case (52 frail elderly patients) and 
control (52 non frail elderly) group.

As regards demographic criteria of the study population, there was no significant difference between cases and controls as regards: age, gender, living arrangement and smoking habits but there was a higher percentage of illiteracy among frail cases.

There was a higher mean number of associated chronic disease in frail cases, there was higher percentage of diabetes mellitus (DM), ischemic heart disease (IHD), hypertension, stroke, visual and hearing impairment among cases. The three most prevalent chronic illnesses among cases were visual impairment, DM, and IHD (the least common were hearing impairment, stroke and chronic liver disease). As for controls the three most prevalent chronic illnesses were chronic obstructive pulmonary disease (COPD), Visual impairment and arthritis Table 1.

Table 2 shows that cases had more assistance \& dependence in ADL \& IADL than controls and the differences where significant statistically ( $\mathrm{P}<0.01$ highly significant). Also there was higher percentage of depression \& cognitive impairment among cases and the difference is highly significant statistically $(\mathrm{P}<0.01)$. The odds ratio were 4.8 for GDS score (which means that cases have 4.8 times the risk of development of depression) \& 20.6 for MMES score (which means that cases have 20.6 times the risk of development of cognitive impairment).

Table 1. Comparison between the two studied groups as regards chronic diseases.

\begin{tabular}{|c|c|c|c|c|c|c|}
\hline & \multicolumn{2}{|c|}{ Cases } & \multicolumn{2}{|c|}{ Controls } & \multirow[b]{2}{*}{$\mathrm{X} 2$} & \multirow[b]{2}{*}{$\mathrm{P}$} \\
\hline & No. & $\%$ & No. & $\%$ & & \\
\hline Diabetes mellitus & 24 & 53.8 & 14 & 26.9 & 4.1 & $0.04^{*}$ \\
\hline IHD & 28 & 53.8 & 9 & 17.3 & 15.1 & $0.000^{* *}$ \\
\hline Hypertension & 26 & 50 & 14 & 26.9 & 5.8 & $0.01^{*}$ \\
\hline Stroke & 10 & 19.2 & 0 & 0 & 6.0 & $0.01^{*}$ \\
\hline COPD & 18 & 34.6 & 19 & 36.5 & 0.4 & 0.8 \\
\hline Arthiritis & 20 & 38.5 & 18 & 34.5 & 0.1 & 0.6 \\
\hline Visual impairement & 40 & 76.6 & 18 & 34.6 & 18.8 & $0.000^{* *}$ \\
\hline Hearing impairment & 8 & 15.4 & 0 & 0 & 8.6 & $0.003^{* *}$ \\
\hline Chronic liver disease & 10 & 19.2 & 5 & 9.6 & 1.9 & 0.1 \\
\hline Thyroid disease & 6 & 11.5 & 0 & 0 & 6.3 & $0.01^{*}$ \\
\hline Anemia & 4 & 7.7 & 0 & 0 & 4.1 & 0.06 \\
\hline
\end{tabular}

${ }^{*} \mathrm{P}<0.05$ significant, ${ }^{* * *} \mathrm{P}<0.01$ highly significant.

Table 2. Comparison between the two studied groups as regards ADL \& IADL assessment, GDS and MMSE score.

\begin{tabular}{|c|c|c|c|c|c|c|}
\hline ADL & Case & $\%$ & Control & $\%$ & $\mathrm{X} 2$ & $\mathbf{P}$ \\
\hline Independent & 10 & 19.2 & 52 & 100 & \multirow{4}{*}{70.4} & \multirow{4}{*}{0.000} \\
\hline Assisted & 31 & 59.6 & 0 & 0 & & \\
\hline Dependent & 11 & 212.2 & 0 & 0 & & \\
\hline IADL & & & & & & \\
\hline Independent & 2 & 3.8 & 39 & 75 & \multirow{3}{*}{61.2} & \multirow{3}{*}{$0.000^{* *}$} \\
\hline Assisted & 27 & 51.9 & 13 & 25.0 & & \\
\hline Dependent & 23 & 44.2 & 0 & 0 & & \\
\hline \multicolumn{7}{|l|}{ GDS } \\
\hline Normal & 20 & 38.5 & 39 & 75 & \multirow{2}{*}{14.1} & \multirow{2}{*}{$0.000^{* *}$} \\
\hline Depressed & 32 & 61.5 & 13 & 25 & & \\
\hline \multicolumn{7}{|l|}{ MMSE Score } \\
\hline Normal & 37 & 71.2 & 51 & 98.1 & \multirow{2}{*}{14.4} & \multirow{2}{*}{$0.000^{* *}$} \\
\hline Impaired & 15 & 28.8 & 1 & 1.9 & & \\
\hline
\end{tabular}

${ }^{*} \mathrm{P}<0.05$ significant, ${ }^{* *} \mathrm{P}<0.01$ highly significant. 


\section{Discussion}

Frailty has been recognized as a common clinical syndrome associated with a high rate of morbidity and mortality [15].

The current study showed no significant association between gender and frailty, However some investigators reported a significant association between female gender and frailty [16].

Our study revealed no significant differences between cases \& controls as regards smoking habits which agrees with Ensrud et al. 2008 who tested 6701 patients 69 years \& older (frailty diagnosed by Study of Osteoporotic Fracture (SOF) frailty index) \& found out no significant differences between robust, intermediate, frail patients in smoking habits [17].

The number of chronic diseases was also a predictor of frailty, independent of the number of physiological systems at abnormal levels this was found by Fried et al. 2009 using data from Woman Health Initiative study (WHS) I \& II [18]. Lists the chronic diseases that have been associated with frailty in published studies of older adults that used standardized disease ascertainment Ternent et al. 2008 found in a study included 1370 elderly that frail subjects were significantly more likely to have hypertension, IHD \& stroke than non-frail subject [19]. Also Avila-funes et al. 2008 stated that hypertension, DM, COPD, arthritis were the most frequent chronic disease among frail participants [5]. Weiss concluded that the most common disease among frail is hypertension, then DM, IHD, stroke [20].

Our study showed that cases had higher percentage of ADL \& IADL affection than controls and the difference was statistically significant. Nearly all studies published in the field of frailty report deterioration in ADL \& IADL In the Women’s Health and Aging Study, Bandeen-Roche et al. 2006 described a cohort of frail adults (aged 70 - 79 years) through 3 years of follow-up, and reported significant outcomes [21]. These outcomes included higher risk of developing disabilities in basic activities of daily living and/or instrumental ADL. Also The Epidemiology of Osteoporosis study by Nourhashemi et al. 2001 stated that impairment in at least one IADL predicts frailty. These data support the hypothesis that frailty may be a physiologic precursor to disability [22].

As in our study Also Chen et al. 2010 found that frail patients had higher prevalence of depressive symptoms than controls and the differences were statistically significant (the study used GDS-15 as in our study) [23]. As well our frail participants had lower MMSE scores \& higher levels of cognitive impairment compared to controls these results get along with a study by Aron et al. 2007 who stated that Increasing frailty is associated with incident Alzheimer's disease(AD) and the rate of cognitive decline in older persons. These findings suggest that frailty and AD may share similar etiologies [24].

In order to asses frailty our study used modified Fried's criteria \& comprehensive geriatric assessment those criteria has been used by Avilla-Funes et al. 2008 who assessed also ADL \& IADL disability [5]; CGA was used to asses frailty by Garrido et al. 2012 [25] \& Bilotta et al. 2010 [26] there are other studies that used part of CGA in the assessment of frailty Nourhashemi et al. 2001 (used IADL) [22] Ottenbacher et al. 2005 (ADL, IADL, MMSE) [27] Mitnitski et al. 2002 composed FI based in CGA items [28], also Jones et al. 2004 diagnosed \& classified frailty into: mild, moderate, sever based upon impairments assessed by CGA. These data point out the importance of CGA in the diagnosis \& assessment of frailty [29].

\section{Conclusion}

Frailty is an important condition among the elderly but it is the essence of geriatric medicine. Frail elderly people had a higher number of associated comorbidities more ADL and IADL dependence and also higher rates of depression and cognitive impairment. So CGA can be used to detect frailty but this issue requires further investigations.

\section{References}

[1] Fried, L.P. and Walston, J. (2003) Frailty and Failure to Thrive. In: Hazzard, W., Blass, J.P., Halter, J.B., et al., Eds., Principles of Geriatric Medicine and Gerontology, 5th Edition, McGraw-Hill, New York, 1487-1502.

[2] Lipschitz, S. (2007) Comprehensive Geriatric Assessment. African Journals Online, CME, 25, 418-420.

[3] Rockwood, K. and Hubbard, R. (2004) Frailty and the Geriatrician. Age and Ageing, 33, 429-430. http://dx.doi.org/10.1093/ageing/afh153

[4] Fried, L.P., Tangen, C.M., Walston, J., et al. (2001) Cardiovascular Health Study Collaborative Research Group. Frail- 
ty in Older Adults: Evidence for a Phenotype. The Journals of Gerontology Series A: Biological Sciences and Medical Sciences, 56, M146-M156. http://dx.doi.org/10.1093/gerona/56.3.M146

[5] Avila-Funes, J.A., Helmer, C., Amieva, H., et al. (2008) Frailty among Community-Dwelling Elderly People in France: The Three-City Study. Journal of Gerontology: Medical Sciences by the Gerontological Society of America, 63A, 1089-1096.

[6] Folstein, M., Folstein, S. and McHug, P. (1975) Minimental State. A Practical Method for Gradient the Cognitive State of Patients for Clinicians. Journal of Psychiatric Research, 12, 189-198. http://dx.doi.org/10.1016/0022-3956(75)90026-6

[7] El-Okl, M. (2002) Prevalence of Alzheimer Dementia and Other Causes of Dementia in Egyptian Elderly. Dissertation, Ain Shams University, Cairo.

[8] Sheikh, J. and Yesavage, J. (1986) Geriatric Depression Scale (GDS) Recent Evidence and Development of a Shorter Version. Clinical Gerontology, 5, 165-173. http://dx.doi.org/10.1300/J018v05n01_09

[9] Shehta, A.S., El-Banouby, M.H., Mortagy, A.K., et al. (1998) Prevalence of Depression among Egyptian Geriatric Community. Geriatric Department Library, Ain Shams University, Cairo, 3-5.

[10] Katz, S., Ford, A., Moswowitz, R., Jackson, B. and Jaffe, M. (1963) Studies of Illness in the Aged. The Index of ADL: Standardized Measure of Biological and Psychological Function. The Journal of the American Medical Association, 185, 914-919. http://dx.doi.org/10.1001/jama.1963.03060120024016

[11] El-Sherpiny, M., Mortagy, A. and Fahy, H. (2000) Prevalence of Hypercholesterolemia among Elderly People Living in Nursing Houses in Cairo. Geriatric Department Library, Ain Shams University, Cairo, 6.

[12] Lawton, M. and Brody, E. (1969) Assessment of Older People: Self-Maintaining and Instrumental Activities of Daily Living. The Gerontologist, 9, 179-186. http://dx.doi.org/10.1093/geront/9.3_Part_1.179

[13] Fillenbaum, G. (1986) The Wellbeing of the Elderly: Approaches to Multi-Dimensional Assessment. World Health Organization, WHO Offset Publication No. 84, Arabic Translation Distributed by the Eastern Mediterranean Regional Office.

[14] Fried, L., Kronmal, R., Newman, A., et al. (1998) Risk Factors for 5 Year Mortality in Older Adults: The Cardiovascular Health Study. The Journal of the American Medical Association, 279, 585-592. http://dx.doi.org/10.1001/jama.279.8.585

[15] Inaki, M., Iturbe, A., Gome, J., et al. (2010) The Frail Elderly, Detection and Treatment. Aten Primaria, 42, $388-339$.

[16] Ottenbacher, K.J., Ostir, G.V., Peek, M.K., et al. (2005) Frailty in Older Mexican Americans. Journal of the American Geriatrics Society, 53, 1524-1531. http://dx.doi.org/10.1111/j.1532-5415.2005.53511.x

[17] Ensrud, K.E., Ewing, S.K., Taylor, B.C., et al. (2008) Comparison of 2 Frailty Indexes for Prediction of Falls, Disability, Fractures, and Death in Older Women. Archives of Internal Medicine, 168, 382-389. http://dx.doi.org/10.1001/archinternmed.2007.113

[18] Fried, L.P., Xue, Q.L., Cappola, A.R., et al. (2009) Nonlinear Multisystem Physiological Dysregulation Associated with Frailty in Older Women: Implications for Etiology and Treatment. The Journals of Gerontology: Series A, Biological Sciences and Medical Sciences, 64, 1049-1057. http://dx.doi.org/10.1093/gerona/glp076

[19] Ternent, S.R., Karmarkar, A., Graham, J., Reistetter, T. and Ottenbacher, K. (2012) Frailty as a Predictor of Falls in Older Mexican Americans. Journal of Aging and Health, 24, 641-653. http://dx.doi.org/10.1177/0898264311428490

[20] Wiess, C.O. (2011) Frailty and Chronic Diseases in Older Adults. Clinics in Geriatric Medicine, 27, 39-52. http://dx.doi.org/10.1016/j.cger.2010.08.003

[21] Bandeen-Roche, K., Xue, Q.L., Ferrucci, L., et al. (2006) Phenotype of Frailty: Characterization in the Women's Health and Aging Studies. The Journals of Gerontology: Series A, Biological Sciences and Medical Sciences, 61, 262-266. http://dx.doi.org/10.1093/gerona/61.3.262

[22] Nourhashémi, F., Andrieu, S., Gillette-Guyonnet, S., et al. (2001) Instrumental Activities of Daily Living as a Potential Marker of Frailty: A Study of 7364 Community-Dwelling Elderly Women (the EPIDOS Study). The Journals of Gerontology: Series A, Biological Sciences and Medical Sciences, 56, M448-M453. http://dx.doi.org/10.1093/gerona/56.7.M448

[23] Chen, C.Y., Wub, S.C., Chenb, L.J., et al. (2010) The Prevalence of Subjective Frailty and Factors Associated with Frailty in Taiwan. Archives of Gerontology and Geriatrics, 50, 43-47.

[24] Aron, S.B., Patricia, A.B., Robert, S.W., et al. (2007) Frailty is Associated with Incident Alzheimer's Disease and Cognitive Declinein the Elderly. Psychosomatic Medicine, 69, 483-489.

[25] Garrido, M.S., and Ponce, C.G. (2012) Ability of the Comprehensive Geriatric Assessment to Predict Frailty in Older People Diagnosed with Cancer in a General Hospital. European Oncology \& Haematology, 8, 85-88.

[26] Bilotta, C., Bowling, A., Casè, A., et al. (2010) Desiemensions and Correlates of Quality of Life According to Frailty 
Status: A cross-Sectional Study on Community-Dwelling Older Adults Referred to an Outpatient Geriatric Service in Italy. Health and Quality of Life Outcomes, 8, 56-63. http://dx.doi.org/10.1186/1477-7525-8-56

[27] Ottenbacher, K.J., Ostir, G.V., Peek, M.K., et al. (2005) Frailty in Mexican American Older Adults. Journal of the American Geriatrics Society, 53, 1524-1531. http://dx.doi.org/10.1111/j.1532-5415.2005.53511.X

[28] Mitnitski, A., Song, X., Skoog, I., et al. (2005) Relative Fitness and Frailty of Elderly Men and Women in Developed Countries and Their Relationship with Mortality. Journal of the American Geriatrics Society, 53, 2184-2189. http://dx.doi.org/10.1111/j.1532-5415.2005.00506.x

[29] Jones, D.M., Song, X. and Rockwood, K. (2004) Operationalizing a Frailty Index from a Standardized Comprehensive Geriatric Assessment. Journal of the American Geriatrics Society, 52, 1929-1933.

http://dx.doi.org/10.1111/j.1532-5415.2004.52521.x 